Article

\title{
The Effect of Elevated Temperatures on the TRM-to-Masonry Bond: Comparison of Normal Weight and Lightweight Matrices
}

\author{
Paraskevi D. Askouni *, Catherine (Corina) G. Papanicolaou and Michael I. Kaffetzakis
}

Structural Materials Laboratory, Department of Civil Engineering, University of Patras, 26504 Rio, Greece; kpapanic@upatras.gr (C.G.P.); mkaffetzakis@upatras.gr (M.I.K.)

* Correspondence: askounip@upatras.gr; Tel.: +30-2610-996-587

Received: 3 April 2019; Accepted: 21 May 2019; Published: 27 May 2019

check for updates

\begin{abstract}
Textile Reinforced Mortar (TRM) is a composite material that has already been successfully used as an externally bonded strengthening means of existing structures. The bond of TRM with various substrates is of crucial importance for determining the degree of exploitation of the textile. However, little is known on the effect of elevated/high temperatures on the TRM-to-substrate bond characteristics while relevant testing protocols are also lacking. This study focuses on the experimental assessment of the TRM-to-masonry bond after exposure of masonry wallettes unilaterally furnished with TRM strips at $120^{\circ} \mathrm{C}$ and $200{ }^{\circ} \mathrm{C}$ for $1 \mathrm{~h}$. The shear bond tests on cooled-down specimens were carried out using the single-lap/single-prism set-up. Two TRM systems were investigated sharing the same type of textile, which is a dry AR glass fiber one (either in a single-layer or in a double-layer configuration) and different matrices: one normal weight (TRNM) and another lightweight (TRLM) of equal compressive strengths. At control conditions (non-heated specimens) and after exposure at a nominal air temperature of $120^{\circ} \mathrm{C}$, both single-layer TRM systems exhibited similar bond capacities. After exposure at a nominal air temperature of $200^{\circ} \mathrm{C}$ single-layer and double-layer TRNM overlays outperformed their TRLM counterparts. A critical discussion is based on phenomenological evidence and measured response values.
\end{abstract}

Keywords: textile reinforced mortar; bond; masonry; normal weight/lightweight aggregates; elevated temperatures

\section{Introduction}

TRM is an innovative composite material suitable for use as externally bonded strengthening means for strengthening or rehabilitation of existing concrete [1] and masonry [2] structures. In the case of masonry structures, and especially those of a monumental character, TRMs comprise an appealing choice since they: (i) allow for minimal geometry and self-weight change of the strengthened structural members, (ii) are chemically, physically, and mechanically compatible with various substrates, (iii) can be reversible (to a certain extent), (iv) can be applied under low temperatures and/or high humidity conditions, and (v) allow for vapor permeability of the substrate.

The quality of bond at both the TRM-to-substrate interface and the textile-to-matrix one is a crucial parameter for the efficient use of this composite material and has received appreciable attention from academia through a number of experimental studies that investigate the effect of individual parameters on bond behavior [3-6]. Nevertheless, there is only a limited number of studies addressing the effect of elevated or high temperatures (ranges being rather arbitrarily defined in each study) on the bond characteristics of TRM systems. To the authors' knowledge, only two studies exist that focus on the experimental investigation of the residual bond capacity of TRM-to-masonry interfaces 
after exposure to elevated/high temperatures. In the study of Maroudas and Papanicolaou [7], a TRM system consisting of a dry AR glass fiber textile embedded in a cementitious matrix was applied on masonry wallettes made of solid clay fair-faced bricks. Single-lap/single-prism tests were conducted after specimens' exposure at $100{ }^{\circ} \mathrm{C}, 200{ }^{\circ} \mathrm{C}$, and $300^{\circ} \mathrm{C}$ for $1 \mathrm{~h}$. It was concluded that the residual shear load that can be undertaken by this type of TRM/masonry interfaces after exposure at $100{ }^{\circ} \mathrm{C}$, $200{ }^{\circ} \mathrm{C}$, and $300{ }^{\circ} \mathrm{C}$ amounts, respectively, to $65 \%, 60 \%$, and $50 \%$ of the respective load reached ambient conditions. In the study of Ombres et al. [8], various TRM systems were applied on masonry wallettes: one made of PBO fiber textile and a cement-based matrix while two other were made of dry basalt fiber textiles (of different aerial weight and grid spacing) and a lime-based mortar. Single-lap/single-prism tests were conducted after specimens' exposure at $100{ }^{\circ} \mathrm{C}, 150{ }^{\circ} \mathrm{C}$, and $200^{\circ} \mathrm{C}$ for $3 \mathrm{~h}$. According to the results, the bond response after specimens' heating was affected by the fibers' type and textiles' density. The residual shear bond load decreased by up to 50\% and 90\% in the case of PBO-TRM and 'heavy' basalt-TRM, respectively, while it remained almost unaffected in the case of the 'light' basalt-TRM ('light' having half the aerial weight of 'heavy'). Furthermore, a numerical model for the simulation of TRMs' bond behavior under different temperatures was proposed by Donnini et al. [9]. For the calibration of the model, double-lap/single-prism shear bond tests were conducted (prisms, in this case, standing for single bricks). The TRM systems comprised textiles with either uncoated (dry) or epoxy-impregnated carbon fiber yarns embedded in a cement-based mortar. Specimens were tested under two different regimes: (i) while, at $120^{\circ} \mathrm{C}$, being conditioned to the same temperature for a duration of $100 \mathrm{~min}$, and (ii) after exposure at $120^{\circ} \mathrm{C}$ for $60 \mathrm{~min}$. It was shown that-when tested under the former heating regime-TRMs with impregnated yarns lost more than half of their bond capacity while the TRMs with dry yarns remained almost unaffected. However, TRMs with impregnated yarns retained almost all of their initial bond capacity when tested under the second heating regime. Lastly, there exist two more studies presenting the results of shear bond tests carried out on concrete specimens furnished with TRM strips both under and after their exposure to elevated/high temperatures. In the study of Ombres [10], single-layered or double-layered TRM overlays consisting of PBO textile and a cement-based matrix were applied on concrete prisms. Single-lap/single-prism shear bond tests were conducted after specimens' exposure at $50{ }^{\circ} \mathrm{C}$ and $100{ }^{\circ} \mathrm{C}$ for $8 \mathrm{~h}$. The bond capacity of the double-layered TRM strips was reduced for both exposure temperatures while the capacity of the single-layered strip was negatively affected only for the higher exposure temperature. In the study of Raoof and Bournas [11], TRM strips with three or four dry carbon textile layers were applied on concrete prisms through a polymer-modified cementitious mortar for the realization of single-lap/double-prism tests. Two testing procedures were followed. According to the first one, specimens were heated at a target temperature $\left(50{ }^{\circ} \mathrm{C}, 75^{\circ} \mathrm{C}, 100^{\circ} \mathrm{C}, 150^{\circ} \mathrm{C}, 200^{\circ} \mathrm{C}, 300^{\circ} \mathrm{C}, 400{ }^{\circ} \mathrm{C}\right.$, and $\left.500{ }^{\circ} \mathrm{C}\right)$ for $60 \mathrm{~min}$ and they were then tested under the same temperature. These specimens were not seriously affected in terms of TRM bond capacity up to a temperature of $400{ }^{\circ} \mathrm{C}$ while their bond load was less than or equal to half of the untreated specimens' load for a temperature of $500{ }^{\circ} \mathrm{C}$. According to the second procedure, specimens were loaded up to a certain percentage of their bond strength $(25 \%, 50 \%$, and $75 \%)$ at ambient conditions and they were then heated up to failure (temperature at failure: approximately $300{ }^{\circ} \mathrm{C}$ when stressed to $25 \%$ and $50 \%$ of their bond strength and approximately $75{ }^{\circ} \mathrm{C}$ when stressed to $75 \%$ of their bond strength).

Review of the existing literature on the topic reveals the lack of commonly accepted testing protocols for the investigation of the heating effect on the TRMs' shear bond performance (either during or post heating) when bonded on various substrates. Temperatures examined are subjectively characterized as 'elevated' or 'high' and heating regimes are arbitrarily selected, which renders comparisons between different experimental campaigns difficult or even invalid. Specimens' treatment prior to testing with a special focus on the moisture content of the TRM overlay (but also of the substrate) is yet another parameter that deserves special attention should rational testing procedures be drafted. Once there, the role of bond critical parameters like the number of textile layers, the textile 
geometry, the type of the matrix, and the type of substrate on heat-struck TRM/substrate joints remains to be investigated.

Although there is no clear definition of what is considered to be the range of "elevated temperatures" as opposed to that of "high temperatures", one would identify (from the available literature) $300^{\circ} \mathrm{C}$ as the boundary temperature between them. Realistic exposure conditions to higher (or much higher) temperatures should be simulated with fire-resembling time-temperature histories (since these temperatures are frequently the result of fire events). The "elevated temperatures" range is of relevance when the aim is to assess the properties of concrete-like materials (TRM, in this case) with surface temperatures close to the ones reached in this paper. Practical examples of situations resulting into such surface concrete (TRM) temperatures are: (i) hot weather exposure (where concrete surface temperatures close to $50{ }^{\circ} \mathrm{C}$ or higher can be recorded, [12]) and (ii) exposure to climatic conditions inside nuclear reactor containments (where the maximum allowed-accident-inflicted or short-term—surface temperatures on concrete elements is set to approximately $175^{\circ} \mathrm{C}$, [13]).

This paper presents the experimental assessment of the residual bond capacity of two externally bonded TRM systems on masonry substrates post their exposure to elevated temperatures. To this purpose, the single-lap/single-prism shear bond test set-up was employed due to its simplicity in terms of specimens' preparation and specimens' handling during the heating treatment. Two TRM systems were investigated to share the same type of textile, namely a dry fiber AR glass textile (either in a single-layer or in a double-layer configuration) and different matrices: one normal weight and another lightweight of equal compressive strengths. It is highlighted that this is one of the first publications involving lightweight matrices for the design of TRM strengthening systems.

\section{Materials, Specimens, and Experimental Program}

\subsection{Materials}

\subsubsection{Masonry}

The masonry substrate was simulated by a wallette made of stack-bonded ridge-faced perforated fired clay bricks and a cement/lime-based mortar. Bricks had a compressive strength of $5 \mathrm{MPa}$ and nominal dimensions $190 \mathrm{~mm} \times 83 \mathrm{~mm} \times 58 \mathrm{~mm}$ (as in length $\times$ width $\times$ height). Masonry joints were approximately $10 \mathrm{~mm}$ thick and were made of an M10 general purpose masonry mortar, according to the EC 6 classification [14], containing cement (CEM II 32.5N), lime, and sand in proportions 1:0.5:5, by volume. The compressive strength and the elastic modulus of the wallettes normal to the mortar joints were equal to $5.8 \mathrm{MPa}(\mathrm{CoV} 10 \%)$ and 3.2 GPa (CoV 19\%), respectively, as determined by testing and complying with the recommendation LUMB1 of RILEM TC 76 Reference [15].

\subsubsection{TRM}

The reinforcement was a woven textile consisting of dry AR glass fiber yarns equally arranged in two orthogonal directions with a $17 \mathrm{~mm}$ mid-yarn spacing (yarns' text being equal to $2450 \mathrm{~g} / \mathrm{km}$ in both directions) and an aerial weight of $300 \mathrm{~g} / \mathrm{m}^{2}$. The textile's tensile strength $\left(f_{\text {tex }}\right)$ and elastic modulus $\left(E_{t e x}\right)$ were determined through lab testing (partly as per standard EN ISO 13934-1 [16] provisions) using seven yarns' strips and were found equal to $505 \mathrm{MPa}(\mathrm{CoV} 11 \%)$ and $83 \mathrm{GPa}(\mathrm{CoV} 17 \%)$, respectively. Two cement-based mortars were used as matrices. The normal weight mortar $(\mathrm{N})$ contained Portland cement (CEM II $42.5 \mathrm{~N})$, fine limestone sand $\left(d_{\max }=2 \mathrm{~mm}\right)$, silica fume $\left(d_{\max }=1 \mu \mathrm{m}\right)$, limestone filler $\left(d_{\max }=120 \mu \mathrm{m}\right)$, and effective water in proportions 1:2.07:0.11:0.28:1.82, by volume. The lightweight mortar (L) contained the same materials' exception being the normalweight sand, which was replaced with pumice sand (cement, pumice sand, silica fume, limestone filler, and effective water in proportions 1:2.07:0.11:0.28:1.61, by volume). The density of the normal weight and lightweight mortar was equal to $2113 \mathrm{~kg} / \mathrm{m}^{3}$ and $1760 \mathrm{~kg} / \mathrm{m}^{3}$, respectively. The compressive and flexural strengths of the mortars were determined at 28 days, according to standard EN 1015-11 [17], and were, respectively, found to be 
equal to $55 \mathrm{MPa}(\mathrm{CoV} 11 \%)$ and $5 \mathrm{MPa}(\mathrm{CoV} 18 \%)$ for the normal weight mortar and $55 \mathrm{MPa}(\mathrm{CoV} 9 \%)$ and $3 \mathrm{MPa}(\mathrm{CoV} 14 \%)$ for the lightweight one. It is noted that the prisms for the mortars' mechanical characterization were cast using a part of the total mortar batches mixed for the cast of the TRM strips and they were cured next to the reinforced masonry prisms (see Section 2.2). The tensile response of the Textile Reinforced Normal Weight Mortar (TRNM) and the Textile Reinforced Lightweight Mortar (TRLM) was determined for both single-layer and double-layer coupons, according to the procedure described in AC434 ICC-ES [18] (three identical specimens per coupons' configuration) and is depicted in Figure 1 while their tensile strength $\left(f_{T R M}\right)$ and the corresponding axial strain $\left(\varepsilon_{T R M}\right)$ is presented in Table 1. From the experimental axial tensile stress versus axial tensile strain curves shown in Figure 1, it is deducted that the response of the single-layer specimens does not qualify as that of a strain-hardening material. This is attributed to the low (longitudinal) fibers' volume fraction. Lightly reinforced cementitious matrices (like the single-layer coupons used herein) exhibit: (i) substantial drops of the load corresponding to the formation of the first (and of any other) crack with this loss of the load carrying capacity being irrecoverable after the formation of each crack, (ii) limited crack formation capacity, and (iii) zero or slight strain hardening (as the result of the fibers' inadequacy to effectively bridge the cracks). On the other hand, double-layer specimens present a strain-hardening response, which could be idealized as trilinear up to failure consisting of an initial uncracked stage followed by a crack development one and a final post-cracked stage. In both cases of single-layered and double-layered coupons, the failure mode was due to load-aligned fibers' slippage from within the mortar and simultaneous fibers' fracture during the enlargement of a previously created mortar crack.

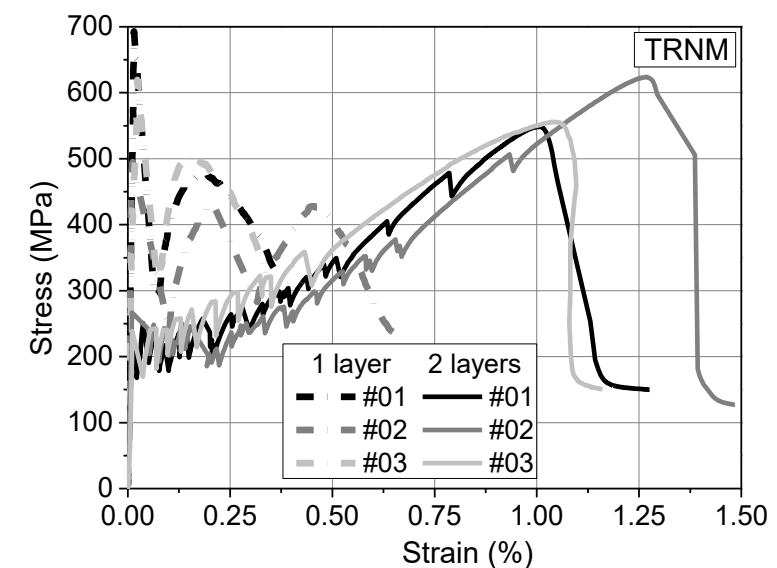

(a)

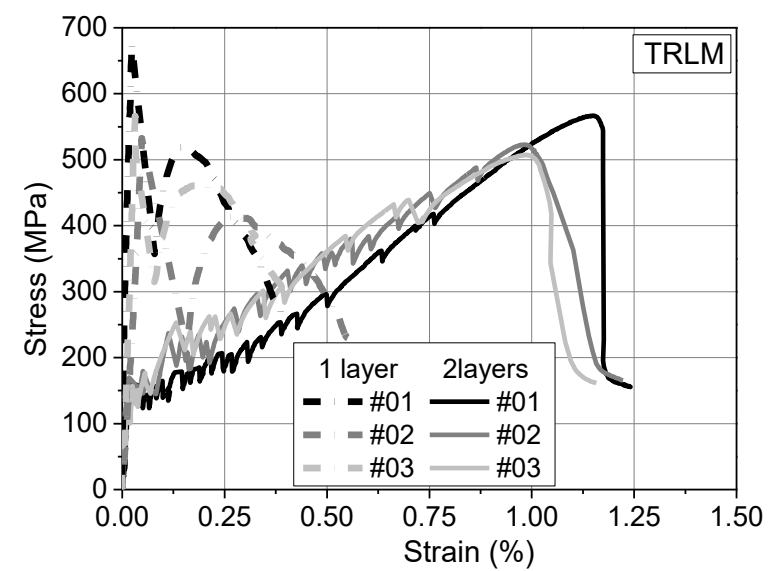

(b)

Figure 1. Axial tensile stress versus axial tensile strain curves of: (a) TRNM (Textile Reinforced Normal Weight Mortar) and (b) TRLM (Textile Reinforced Lightweight Mortar) coupons (stress is calculated by dividing with the load-aligned fibers' cross section).

Table 1. Mechanical characteristics of TRM (Textile Reinforced Mortar) coupons.

\begin{tabular}{|c|c|c|c|}
\hline Coupon's Configuration & $\begin{array}{l}\text { First Crack Stress } \\
\qquad \begin{array}{c}f_{F C R} \\
(\mathrm{MPa}) \\
\{\mathrm{CoV}\}\end{array}\end{array}$ & $\begin{array}{c}\text { Tensile Strength } \\
f_{\text {TRM }} \\
(\mathrm{MPa}) \\
\{\mathrm{CoV}\}\end{array}$ & $\begin{array}{l}\text { Axial Strain Corresponding to } f_{T R M} \\
\qquad \varepsilon_{T R M} \\
(\%) \\
\{\mathrm{CoV}\}\end{array}$ \\
\hline TRNM 1 layer & $604\{17 \%\}$ & $604\{17 \%\}$ & $0.02\{19 \%\}$ \\
\hline TRNM 2 layers & $241\{12 \%\}$ & $576\{7 \%\}$ & $1.11\{13 \%\}$ \\
\hline TRLM 1 layer & $594\{13 \%\}$ & $594\{13 \%\}$ & $0.03\{20 \%\}$ \\
\hline TRLM 2 layers & $151\{17 \%\}$ & $532\{6 \%\}$ & $1.04\{9 \%\}$ \\
\hline
\end{tabular}




\subsection{Specimens}

Shear bond test specimens were designed and constructed (for the most part), according to the recommendation of RILEM TC 250-CSM [19]. Each specimen comprised one wall prism (wallette) reinforced with a single-layer or double-layer TRM overlay on one side, which was cast according to the wet lay-up process (Figure 2). Each mortar layer (2 and 3 for single-layer and double-layer TRMs, respectively) was approximately $4 \mathrm{~mm}$-thick and was toweled flush to the prescribed thickness by means of a $4 \mathrm{~mm}$-thick rubber-cork frame. The TRM overlay (and, hence, the textile strip) was centrally bonded on the wallettes' width-wise. The length and width of each TRM overlay were equal to $250 \mathrm{~mm}$ and $120 \mathrm{~mm}$ (7 yarns), respectively, while its distance from the wall's top edge was equal to $40 \mathrm{~mm}$ so that stress concentration phenomena would be avoided. The textile(s) projected from both sides of the TRM overlay, that is from the top and bottom part of the overlay designated herein as "loaded end" and "free end", respectively (Figure 2). Specimens were moist-cured for 7 days (covered with wet burlaps) and then stored in lab conditions $\left(20^{\circ} \mathrm{C} \pm 2{ }^{\circ} \mathrm{C}, 65 \% \mathrm{RH}\right)$ for 21 more days until pre-heating treatment, heating, and final testing. Prior to testing, the extremity/extremit(ies) of the projecting textile(s) from the loaded end of the TRM overlays were sandwiched between either two or three glued-on fiber-reinforced polymer (FRP) tabs depending on the number of textile layers (i.e., one or two, respectively).

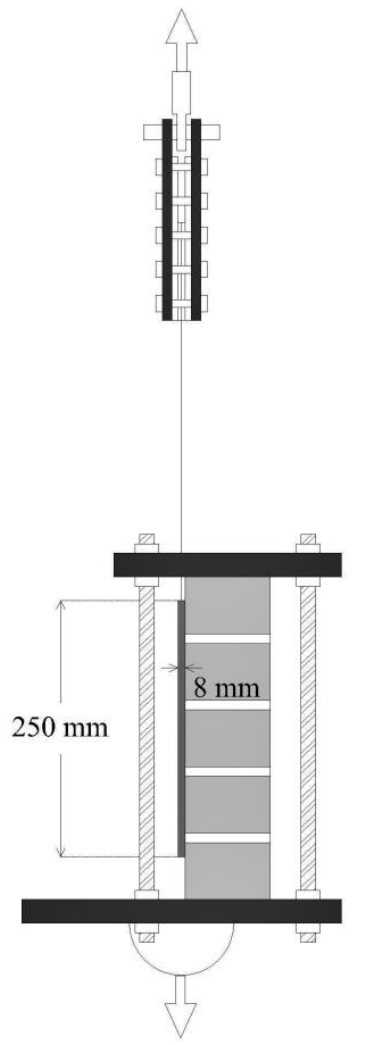

Side view Single TRM overlay

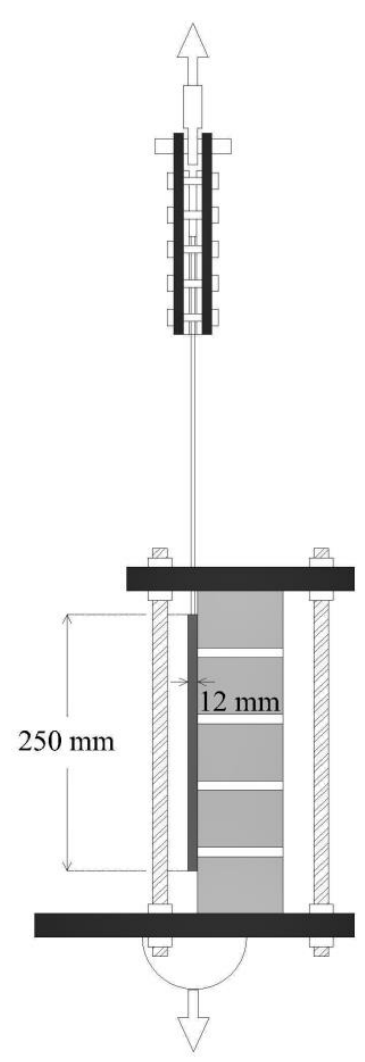

Side view

Double TRM overlay

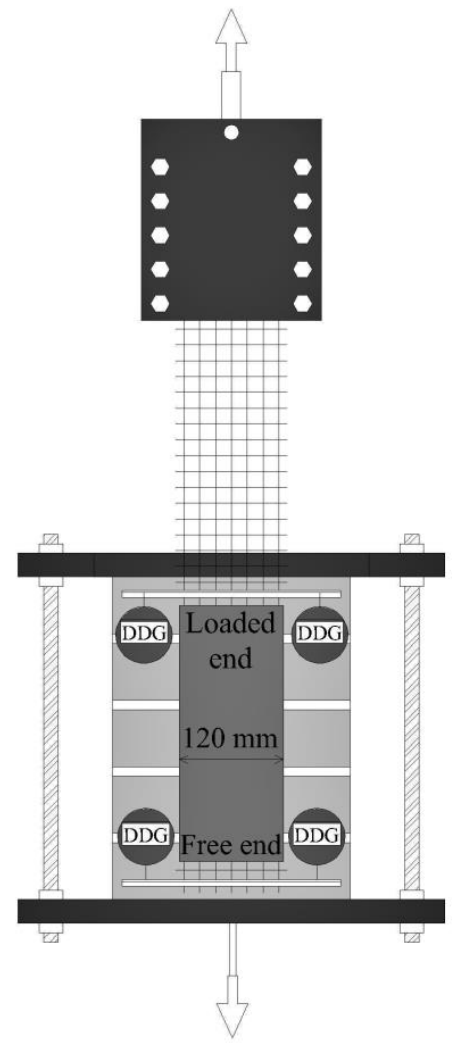

Front view

Figure 2. Single-lap/single-prism shear bond test set-up.

\subsection{Experimental Program}

\subsubsection{Test Plan}

In total, 30 specimens were constructed: half of them (15) were furnished with Textile Reinforced Normal Weight Mortar overlays and the rest (15) with Textile Reinforced Lightweight Mortar ones. Specimens were tested at ambient temperature $\left(20^{\circ} \mathrm{C}\right.$-control specimens) and, after exposure, 
at $120^{\circ} \mathrm{C}$ and $200{ }^{\circ} \mathrm{C}$. For both minimum and maximum temperatures $\left(20^{\circ} \mathrm{C}\right.$ and $\left.200{ }^{\circ} \mathrm{C}\right)$, prisms furnished with both single-layer and double-layer TRM strips were tested. For $120^{\circ} \mathrm{C}$, prisms tested bore only single-layer TRM strips. Three identical specimens were tested per case. The specimens' notation has the form of Tx_Sy_z_n (see also Table 2), where $x$ is the nominal exposure temperature (T) in ${ }^{\circ} \mathrm{C}$, $\mathrm{y}$ is the number of textile strips $(\mathrm{S})$, $\mathrm{z}$ is the type of mortar used as a matrix ( $\mathrm{N}$ or $\mathrm{L}$ ), and $\mathrm{n}$ is the specimen number in a group of identical specimens. The bond length of the TRM strip $(250 \mathrm{~mm})$ was selected so as to ensure its adequate anchoring on the substrate.

Table 2. Experimental results.

\begin{tabular}{|c|c|c|c|c|c|c|c|c|c|c|}
\hline Specimen & $\begin{array}{c}\text { Temperature } \\
\left({ }^{\circ} \mathrm{C}\right)\end{array}$ & $\begin{array}{c}\text { Tex Strip } \\
\#\end{array}$ & $\begin{array}{c}\text { TKLE } \\
\left({ }^{\circ} \mathrm{C}\right) \\
\{\mathrm{CoV}\}\end{array}$ & $\begin{array}{l}\text { TKFE } \\
\left({ }^{\circ} \mathrm{C}\right) \\
\{\mathrm{CoV}\}\end{array}$ & $\begin{array}{c}\text { TKM } \\
\left({ }^{\circ} \mathrm{C}\right) \\
\{\mathrm{CoV}\}\end{array}$ & $\begin{array}{c}\sigma_{\max } \\
\text { (MPa) }\end{array}$ & $\begin{array}{c}\sigma_{\max , \text { average }} \\
(\mathrm{MPa}) \\
\{\mathrm{CoV}\}\end{array}$ & $\begin{array}{l}d_{r, \max } \\
(\mathrm{mm})\end{array}$ & $\begin{array}{c}d_{r, \max , \text { average }} \\
(\mathrm{mm}) \\
\{\mathrm{CoV}\}\end{array}$ & $\begin{array}{c}s_{\max } \\
(\mathrm{mm})\end{array}$ \\
\hline T20S1N01 & 20 & 1 & \multirow{3}{*}{-} & \multirow{3}{*}{ - } & \multirow{3}{*}{-} & 313.28 & \multirow{3}{*}{$\begin{array}{c}344.36 \\
\{11 \%\}\end{array}$} & 0.26 & \multirow{3}{*}{$\begin{array}{c}0.28 \\
\{29 \%\}\end{array}$} & \multirow[t]{3}{*}{0.005} \\
\hline T20S1N02 & 20 & 1 & & & & 335.91 & & 0.22 & & \\
\hline T20S1N03 & 20 & 1 & & & & 383.88 & & 0.38 & & \\
\hline T20S2N01 & 20 & 2 & \multirow{3}{*}{-} & \multirow{3}{*}{ - } & \multirow{3}{*}{-} & 340.72 & \multirow{3}{*}{$\begin{array}{c}330.53 \\
\{7 \%\}\end{array}$} & 0.48 & \multirow{3}{*}{$\begin{array}{c}0.66 \\
\{32 \%\}\end{array}$} & \multirow[t]{3}{*}{0.07} \\
\hline T20S2N02 & 20 & 2 & & & & 305.58 & & 0.90 & & \\
\hline T20S2N03 & 20 & 2 & & & & 345.30 & & 0.61 & & \\
\hline T20S1L01 & 20 & 1 & \multirow{3}{*}{-} & \multirow{3}{*}{ - } & \multirow{3}{*}{-} & 375.32 & \multirow{3}{*}{$\begin{array}{c}377.57 \\
\{6 \%\}\end{array}$} & 0.13 & \multirow{3}{*}{$\begin{array}{c}0.11 \\
\{17 \%\}\end{array}$} & \multirow[t]{3}{*}{0.005} \\
\hline T20S1L02 & 20 & 1 & & & & 355.49 & & 0.09 & & \\
\hline T20S1L03 & 20 & 1 & & & & 401.90 & & 0.11 & & \\
\hline T20S2L01 & 20 & 2 & \multirow{3}{*}{ - } & \multirow{3}{*}{-} & \multirow{3}{*}{ - } & 341.48 & \multirow{3}{*}{$\begin{array}{c}369.49 \\
\{7 \%\}\end{array}$} & 0.66 & \multirow{3}{*}{$\begin{array}{c}0.69 \\
\{18 \%\}\end{array}$} & \multirow[t]{3}{*}{0.04} \\
\hline T20S2L02 & 20 & 2 & & & & 391.14 & & 0.83 & & \\
\hline T20S2L03 & 20 & 2 & & & & 375.86 & & 0.59 & & \\
\hline T120S1N01 & 120 & 1 & \multirow{3}{*}{$\begin{array}{c}51 \\
\{8 \%\}\end{array}$} & \multirow{3}{*}{$\begin{array}{c}45 \\
\{9 \%\}\end{array}$} & \multirow{3}{*}{$\begin{array}{c}63 \\
\{20 \%\}\end{array}$} & 337.66 & \multirow{3}{*}{$\begin{array}{c}341.74 \\
\{2 \%\}\end{array}$} & 0.28 & & 0.07 \\
\hline T120S1N02 & 120 & 1 & & & & 348.36 & & 0.36 & $\begin{array}{l}0.38 \\
27 \%\end{array}$ & \\
\hline T120S1N03 & 120 & 1 & & & & 339.19 & & 0.49 & & \\
\hline T120S1L01 & 120 & 1 & & & & 316.27 & & 0.39 & & 0.03 \\
\hline T120S1L02 * & 120 & 1 & $\begin{array}{c}49 \\
\{1 \%\}\end{array}$ & $\begin{array}{c}49 \\
\{17 \%\}\end{array}$ & $\begin{array}{c}53 \\
111 \%\end{array}$ & - & $\begin{array}{l}331.55 \\
56 \%\}\end{array}$ & - & $\begin{array}{l}0.46 \\
22 \% \%\end{array}$ & \\
\hline T120S1L03 & 120 & 1 & & & & 346.83 & & 0.54 & & \\
\hline T200S1N01 & 200 & 1 & & & & 345.30 & & 0.49 & & 0.10 \\
\hline T200S1N02 & 200 & 1 & $\{14 \%\}$ & $\begin{array}{c}99 \\
\{13 \%\}\end{array}$ & 109 & 319.33 & $\begin{array}{l}317.29 \\
59 \% 1\end{array}$ & 0.47 & 0.48 & \\
\hline T200S1N03 & 200 & 1 & & & & 287.24 & & 0.48 & & \\
\hline T200S2N01 & 200 & 2 & & & & 300.23 & & 0.74 & & 0.12 \\
\hline T200S2N02 & 200 & 2 & $\begin{array}{l}121 \\
17 \%\}\end{array}$ & $\begin{array}{l}102 \\
19 \%\}\end{array}$ & 118 & 306.34 & 322.13 & 0.57 & $\begin{array}{l}0.56 \\
32 \%\end{array}$ & \\
\hline T200S2N03 & 200 & 2 & & & & 359.82 & & 0.38 & & \\
\hline T200S1L01 & 200 & 1 & & & & 238.35 & & 0.49 & & 0.06 \\
\hline T200S1L02 & 200 & 1 & 117 & 105 & 118 & 282.66 & $\begin{array}{l}251.59 \\
\{11 \%\}\end{array}$ & 0.37 & $\begin{array}{l}0.40 \\
1210 / 1\end{array}$ & \\
\hline T200S1L03 & 200 & 1 & & & & 233.77 & & 0.33 & & \\
\hline T200S2L01 & 200 & 2 & & & & 233.00 & & 0.79 & & 0.08 \\
\hline T200S2L02 & 200 & 2 & $\begin{array}{c}125 \\
\{12 \%\}\end{array}$ & $\begin{array}{l}111 \\
\{3 \%\}\end{array}$ & $\begin{array}{l}133 \\
\{4 \%\}\end{array}$ & 276.30 & $\begin{array}{l}271.63 \\
\{13 \%\}\end{array}$ & 0.55 & $\begin{array}{l}0.59 \\
\{32 \%\}\end{array}$ & \\
\hline T200S2L03 & 200 & 2 & & & & 305.58 & $\{13 \%\}$ & 0.42 & & \\
\hline
\end{tabular}

${ }^{*}$ Machine stopped working unexpectedly during testing.

\subsubsection{Pre-Heating Treatment and Heating Regime}

Prior to subjecting the specimens to the prescribed heating regime, all of them were inserted in an electrical oven at a constant temperature of $40{ }^{\circ} \mathrm{C}$ for $24 \mathrm{~h}$ with the aim of bringing them to a state of approximately equal moisture content. Upon removal from the oven and until their exposure to elevated temperatures, specimens were wrapped in a PVC membrane in order to prevent moisture exchange with the atmosphere. For heating to $120^{\circ} \mathrm{C}$ and $200{ }^{\circ} \mathrm{C}$, the electrical oven (the same used for the drying sequence) was preheated prior to specimens' placement at a temperature higher than the target one in order to counterbalance the heat loss due to door opening. Each specimen rested in the oven for $1 \mathrm{~h}$ under the target temperature and remained undisturbed after turning the oven off until its temperature reached the ambient one. All heated specimens were tested upon completion of the heating-cooling regime. Figure 3 presents the time history of the specimens' preparation and treatment. 


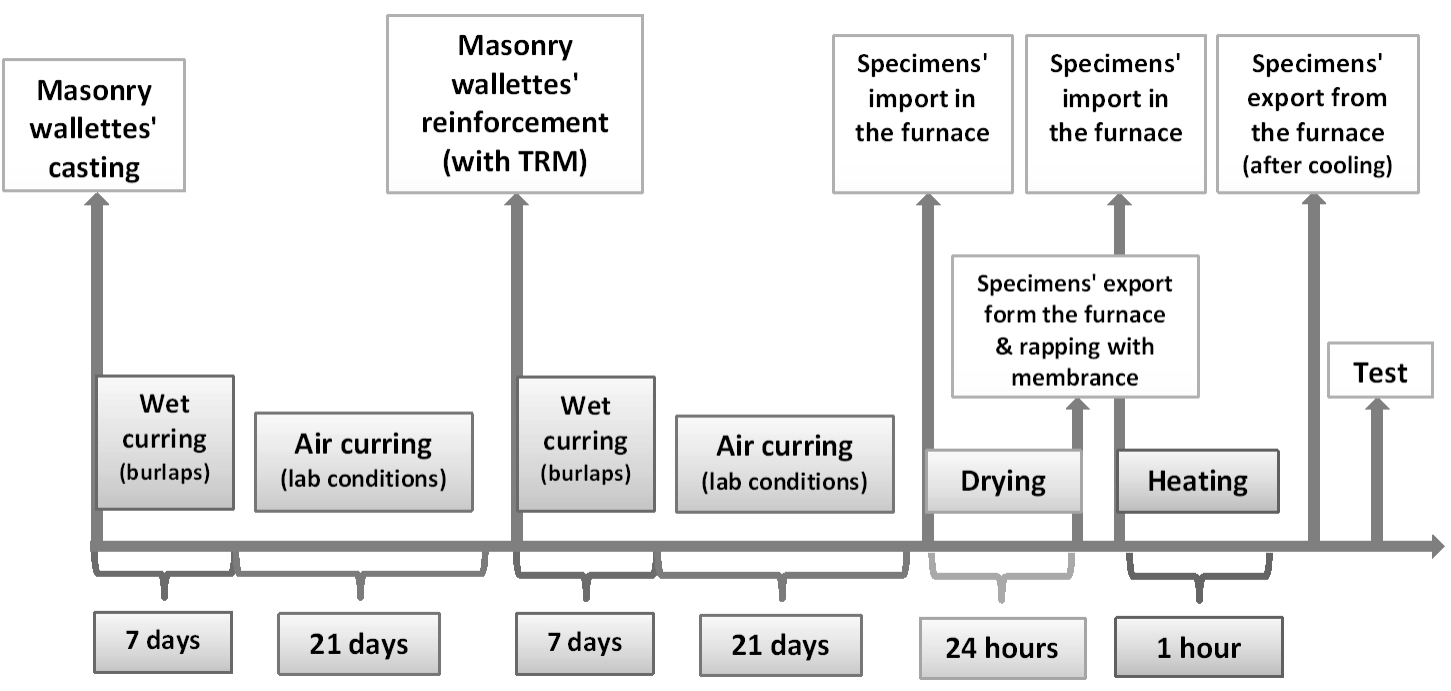

Figure 3. Time history of specimens' preparation and treatment.

For specimens subjected to the previously described heating-cooling regime, the free part of the wallette surface furnished with the composite overlay had been covered with the same mortar used for the TRM so that real-life conditions were simulated during heating. For these specimens, the protection of the projecting bare textile was achieved using a combination of ceramic wool insulation and rock mineral wool insulation with aluminum coating, as depicted in Figure 4a. It is also noted that specimens were placed horizontally in the furnace so that heating coming from above was evenly distributed on the TRM strip, which faced upward (see Figure 4b). Four K-type thermocouples were used as heat sensors (Figure 4). One was placed at a close distance from the specimen's surface in order to record the air temperature (TKA). The furnace temperature was adjusted so that the air temperature recorded by TKA was equal with the target one. The rest of the sensors (insulated against radiation heating) were applied on the specimen as follows: two of them were attached on the textile projecting from each end of the TRM strip [one close to the loaded end (TKLE) and another close to the free end (TKFE)] while another sensor was placed on the strip's surface at a distance of $50 \mathrm{~mm}$ to $100 \mathrm{~mm}$ from the loaded end (TKM).

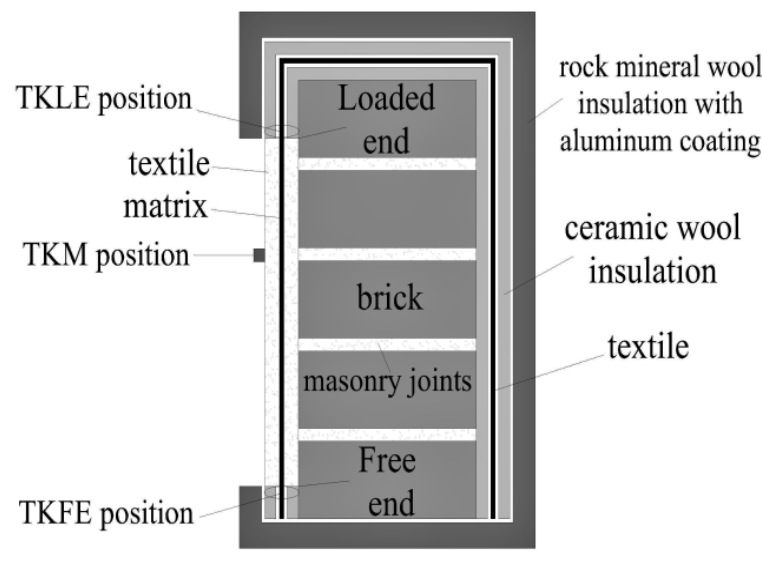

(a)

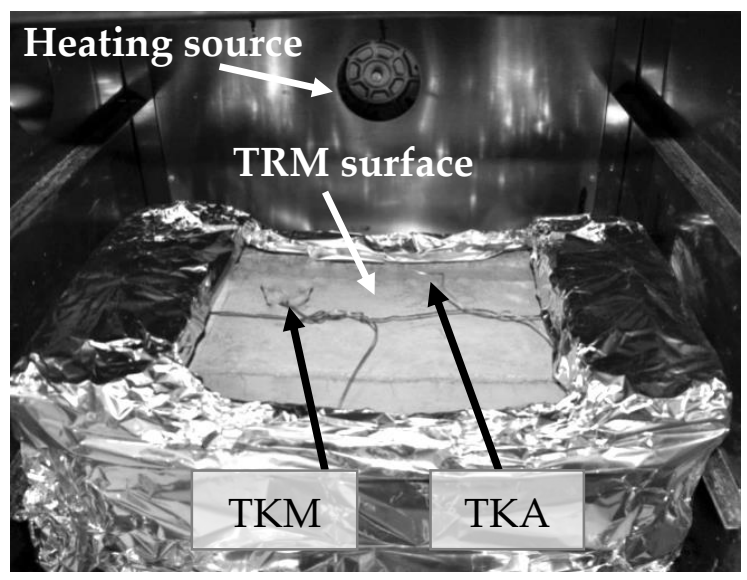

(b)

Figure 4. Insulated specimen (instrumented with thermocouples): (a) side view and (b) inside the electrical furnace; (K-type thermocouple: close to Loaded End, TKLE; close to Free End, TKFE; on the strip's surface, TKM; close to specimen's surface, TKA) 


\subsubsection{Shear Bond Tests Set-Up}

For the execution of the single-lap/single-prism shear bond tests, each wallette was fitted in a steel frame. Then, the textile(s) projecting from the loaded end was (were) connected to the fixed part of the machine through a joint that provided full in-plane and partial out-of-plane rotation capacity (Figure 2-Section 2.2). The connection was realized by clamping the FRP tab between two bolted hinged steel plates. During testing, the projecting textile(s) was (were) being pulled away from the bonded TRM overlay. Tests were carried out at a piston displacement-controlled mode using a servohydraulic testing machine (load capacity $250 \mathrm{kN}$ ). The displacement rate was set to $0.005 \mathrm{~mm} / \mathrm{s}$. Each specimen was instrumented (see Figure 2-Section 2.2) with: (i) two digital dial gauges (DDG) firmly attached on the wall close to the overlay's loaded end acting against an aluminum plate glued on the first transversal yarn of the pulled textile in order to record the textile's relative displacement in respect to the wallette (under the assumption that the TRM-to-substrate slip was null), (ii) two DDG glued on the wall close to the overlay's free end acting against an aluminum plate glued on the second transversal yarn of the projecting textile in order to record the textile's slip (these sensors were applied only on the Tx_Sy_z_01 specimen of each group of identical specimens).

\section{Results}

\subsection{Heating Effect}

Visual inspection of specimens right after the conclusion of the heating-cooling regime revealed the formation of fine cracks on the top mortar layer of the TRM overlays. Cracks did not seem to propagate through the entire thickness of the TRM overlays (looking from the side of the TRM strips). In the case of single-layer TRM overlays, the number of cracks increased with increasing exposure temperature for both types of mortars whereas TRLMs were more prone to cracking than their TRNM counterparts. In the case of normal weight mortar, double-layer TRM overlays remained uncracked after specimens' exposure at $200{ }^{\circ} \mathrm{C}$ while, in the case of lightweight mortar, fewer cracks appeared on the double-layer TRM overlays than on the single-layer ones.

These fine cracks are attributed to differential shrinkage/swelling phenomena dissimilar between TRNM/masonry and TRLM/masonry joints. The 24-h-long drying at $40{ }^{\circ} \mathrm{C}$ was not sufficient for the complete drying of the TRM strips' matrices. The evaporation of the remaining moisture in the normal weight matrix (during the heating-cooling regime) is the cause for restrained shrinkage of the TRNM strip (while bed joints' mortar is also undergoing shrinkage but at a different pace). For lightweight matrices, restrained volume change phenomena are more complex. Initially, that is after the end of the (wet) curing period, the moisture content buffered in the lightweight (porous) aggregates (pumice, in this work, used in a fully saturated condition during mixing) is fed back into the paste, which causes swelling. The latter (depending on its magnitude) can even be perceived as a crack prevention mechanism due to differential volume changes. Nevertheless, during drying (especially during heating), a larger quantity of moisture escapes from the lightweight mortar in comparison to the normal weight one, which results in larger deformations of the TRLM strip due to differential shrinkage and in a lengthier TRLM shrinkage evolution period. Larger differential shrinkage deformations of the TRLM strip cause cracking provided that the bond strength of the TRM/substrate interface is larger than the tensile stresses developed in the TRLM strip due to shrinkage, which, in turn, should be larger than the tensile strength of the mortar comprising the strip. Lastly, as in all cementitious fiber-reinforced materials, shrinkage cracking was limited by increasing the fiber volume fraction $(0.68 \%$ and $0.92 \%$ for single-layer and double-layer TRMs, respectively).

\subsection{Failure Mode}

All specimens failed due to textile slippage from within the mortar with simultaneous sleeve fibers' fracture along the textile projecting from the TRM overlay's loaded end (Figure 5). The pre-existing 
surface cracks in the matrix - which had been created during the heating-cooling regime - were not increased in number during shear bond testing.

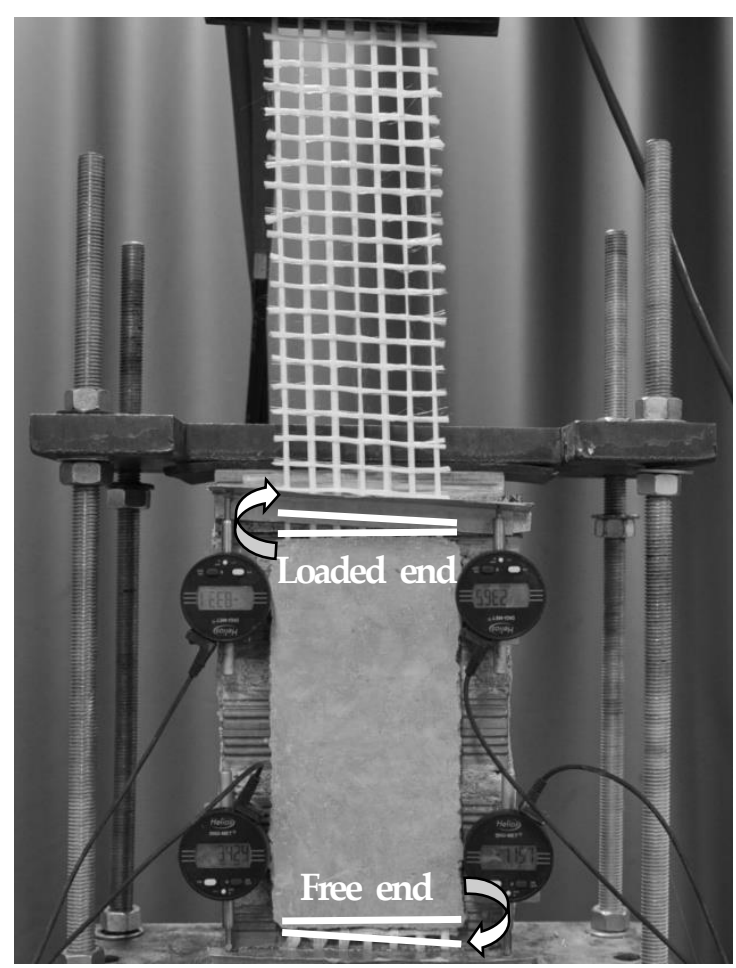

Figure 5. Specimen at failure.

\section{Discussion}

The experimental results are presented in Table 2 in terms of: (i) the average-for each group of identical specimens-temperature recorded by the TKLE, TKFE, and TKM thermocouples at the end of $1 \mathrm{~h}$ exposure to the target furnace temperature, (ii) the maximum textile axial stress $\left(\sigma_{\max }\right)$ computed as the ratio of the maximum load carried by the TRM overlay to the cross sectional area of the longitudinal (load-aligned) fibers (equal to $6.545 \mathrm{~mm}^{2}$ for the single-layer TRM overlay and $13.090 \mathrm{~mm}^{2}$ for the double-layer one), (iii) the corresponding relative displacement of the textile with respect to the wall $\left(d_{r, \max }\right)$ being equal to the average of the readings from the DDG at the loaded end and (iv) the corresponding textile slip from within the mortar $\left(s_{\max }\right)$ being equal to the average of the readings from the DDG at the free end.

As far as the thermocouples' readings are concerned, temperature values do not vary significantly in relation to the sensors' position (per specimens' group), the number of textile layers (per mortar type), and the type of mortar (for the same number of textile layers). The TRM surface temperature and the temperature of the projected textile close to the loaded and free end for all types of TRM overlays investigated are found to be equal to roughly half of the ambient air temperature (for both mortar types: $50^{\circ} \mathrm{C}$ for single-layer TRM overlays exposed to $120{ }^{\circ} \mathrm{C} ; 110^{\circ} \mathrm{C}$ and $\sim 120{ }^{\circ} \mathrm{C}$ for single-layer and double-layer TRM overlays exposed to $200^{\circ} \mathrm{C}$, respectively). In more detail, the rate of TRM surface and textile temperatures over the nominal exposure (air) temperature increase with increasing exposure temperature. The evolution of the thermocouples' values during the hour-long exposure is depicted in Figure 6 for three representative specimens furnished with TRLM overlays (the respective temperature records concerning specimens with TRNM overlays are almost identical). 

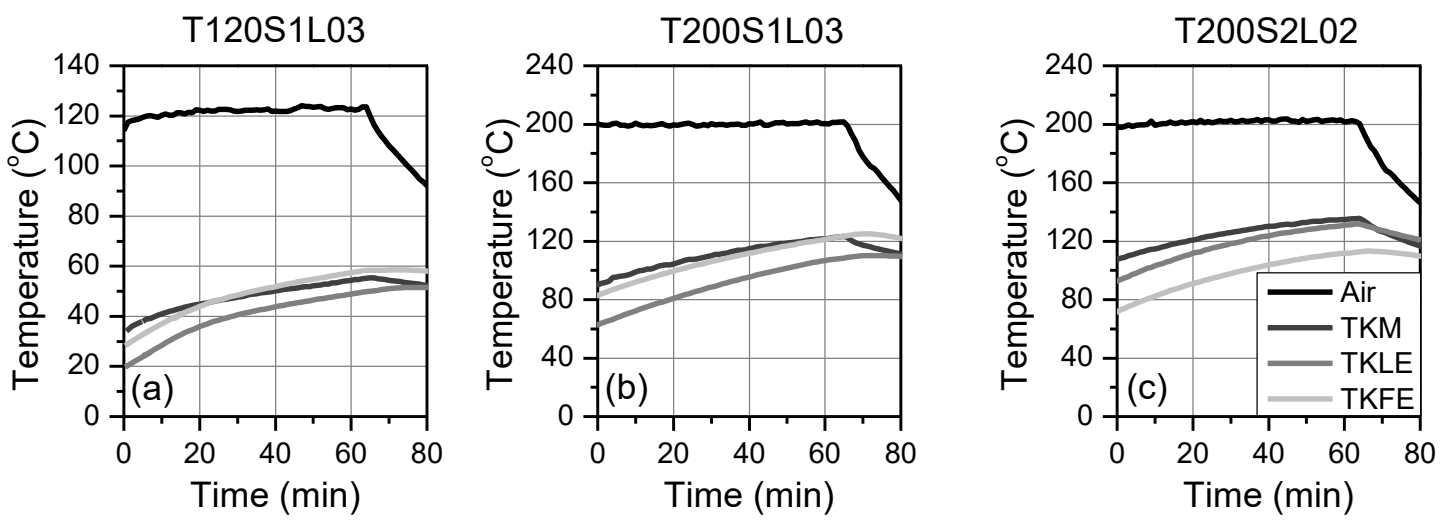

Figure 6. Thermocouples' temperature profiles for representative specimens: (a) T120S1L03, (b) T200S1L03, and (c) T200S2L02.

The maximum textile axial stress, $\sigma_{\max }$, (average for each specimen group) versus the target furnace temperature plot is presented in Figure $7 \mathrm{a}$ for each type of mortar. It is observed that, at control conditions (non-heated specimens: $20^{\circ} \mathrm{C}$ in Table 2) and after exposure at a nominal air temperature of $120^{\circ} \mathrm{C}$, both single-layer TRM systems (TRNM and TRLM) exhibit similar bond capacity differences between them being unimportant considering the statistical performance of each pair of compared specimen groups. The same does not apply for the nominal exposure temperature of $200{ }^{\circ} \mathrm{C}$ for which single-layer and double-layer TRNM overlays outperform the respective TRLM ones in terms of residual bond capacity.

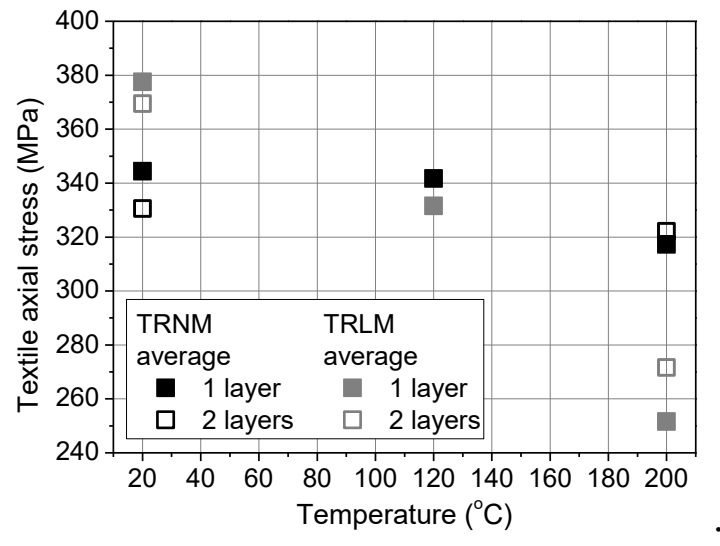

(a)

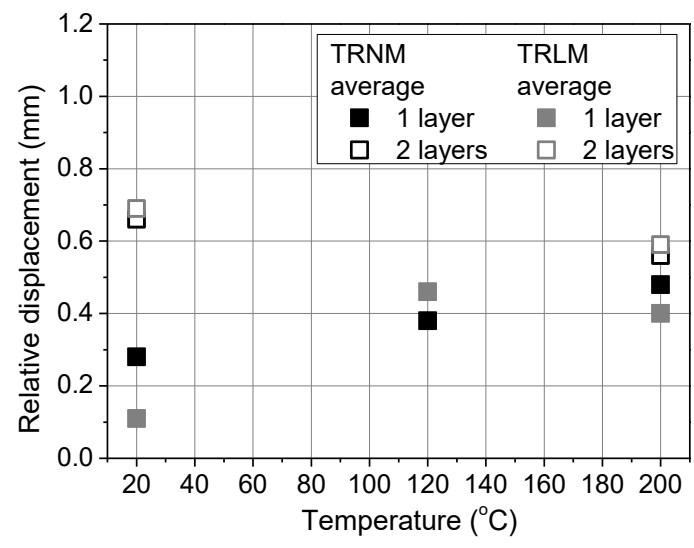

(b)

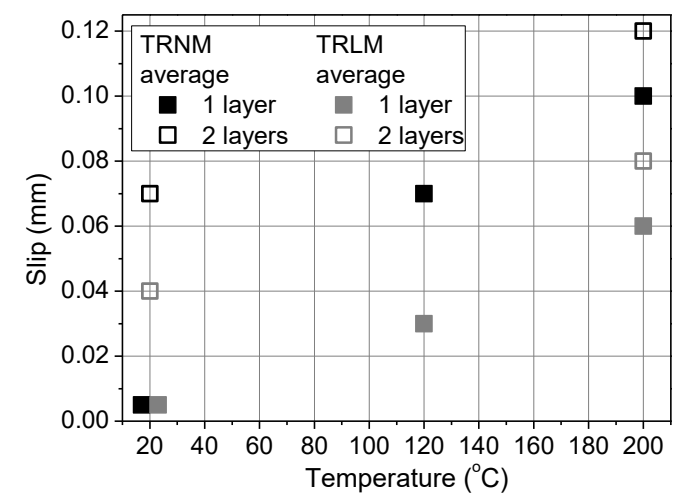

(c)

Figure 7. (a) Maximum textile axial stress, $\sigma_{\max }$, and corresponding (b) relative displacement, $d_{r, \max }$, and (c) slip, $s_{\max }$, versus nominal exposure temperature. 
Per type of matrix considered, the following trends are observed. For the same thermal treatment prior to testing (none, or exposure at either $120^{\circ} \mathrm{C}$ or $200{ }^{\circ} \mathrm{C}$ for $1 \mathrm{~h}$ ), $\sigma_{\max }$ stresses corresponding to double-layer overlays are comparable to those of single-layer ones (as also noticed by Askouni and Papanicolaou [6] for specimens tested without having been previously heated). The effect of exposure temperature increase prior to testing does not seem to substantially affect the residual bond capacity of single-layer and double-layer TRNM overlays. The maximum textile axial stress remains almost unchanged for specimens subjected to $120^{\circ} \mathrm{C}$ and decreases by less than $10 \%$ for specimens subjected to $200{ }^{\circ} \mathrm{C}$ in comparison with the maximum textile axial stress of the reference specimens. The same does not apply for TRLM overlays. In this case, the maximum textile axial stress decreases slightly (by $14 \%$ ) for specimens subjected to $120^{\circ} \mathrm{C}$ (with single-layer TRMs) and by $50 \%$ and $36 \%$ for specimens subjected to $200^{\circ} \mathrm{C}$ with single-layer and double-layer overlays, respectively, in comparison to the maximum textile axial stress of the reference specimens. An increase of mortar thickness (to accommodate higher fiber volume fractions, i.e., more textile layers) seems to be beneficial in terms of residual bond capacity.

In TRLM overlays, the maximum textile axial stress decrease for increasing exposure temperature is mainly attributed to the cracking that this exposure caused. Despite the fact that these cracks did not increase in number or in width during shear bond testing, it is believed that they comprised textile-to-matrix bond breaker points. Bond damage could also occur as the combined result of: (i) early-age swelling and (ii) stress buildup during moisture evaporation by heating. The latter should theoretically be minimal in lightweight mortars with highly porous aggregates. However, according to Chandra and Berntsson [20], lightweight cementitious matrices with a dense cement paste (like the one used herein) exhibit low vapor permeability and, hence, moisture transport results in the development of high internal stresses. The latter is expected to mainly affect the bond between the textile and the top (atmosphere-exposed) mortar layer. In double layer systems, the stress-relieving effect of higher fibers' content is combined with the preservation of the bond quality of the bottom textile layer with the surrounding (unexposed) matrix.

The plot of the textile relative displacement corresponding to the maximum textile axial stress, $d_{r, \max }$, versus the target furnace temperature is presented in Figure $7 \mathrm{~b}$ for each TRM configuration. These displacement values are less reliable in comparison to the stress ones due to their (inherently) higher CoV. Therefore, the corresponding data trends are only qualitatively commented. Average $d_{r, m a x}$ values: (i) depend more on the number of textile layers than on the type of matrix used and (ii) increase with increasing exposure temperature for single-layer configurations (for which $d_{r}$ measurement is more straightforward compared to double-layer ones). The relative displacement is the result of two synergistic phenomena: the elongation and the slippage of the longitudinal yarns' fibers in the matrix (see Askouni and Papanicoloaou [5]). In the case of single-layer TRNM overlays, the increase of $d_{r}$ is attributed mainly to the increase of the textile slippage from within the normal weight mortar with increasing exposure temperature (see slip values recorded by DDG at the TRNM overlays' free ends in Figure 5c). In the case of TRLM overlays, the textile-to-matrix bond is more severely damaged by volume change phenomena (especially those heat-induced), which lead also to sleeve fibers' rupture within the matrix (hence, the lower slip values compared to single-layer TRNMs in Figure 7c). Average $d_{r, \max }$ values of double-layer TRM overlays are higher than the respective values of single layer ones. This is in agreement with observations done by Askouni and Papanicolaou [6] who also provide the relevant reasoning.

The response (textile axial stress versus relative displacement curves) of representative specimens of both TRM systems (TRNM and TRLM) is given in Figure 8. Most curves can be approximated as bilinear up to failure. In the first branch, both components (textile and mortar) behave in an elastic composite manner. The second branch extends between the change of the curve's inclination and the maximum load where the bond between fiber yarns and matrix is gradually deteriorated along a part of the bond length. It is highlighted that failure manifests the commencement of the load-aligned yarns' debonding from the matrix in combination with their sleeve fibers' progressive 
rupture. Post-peak stress decrease is significantly more rapid for the TRLM overlays due to the brittleness of the lightweight mortar.

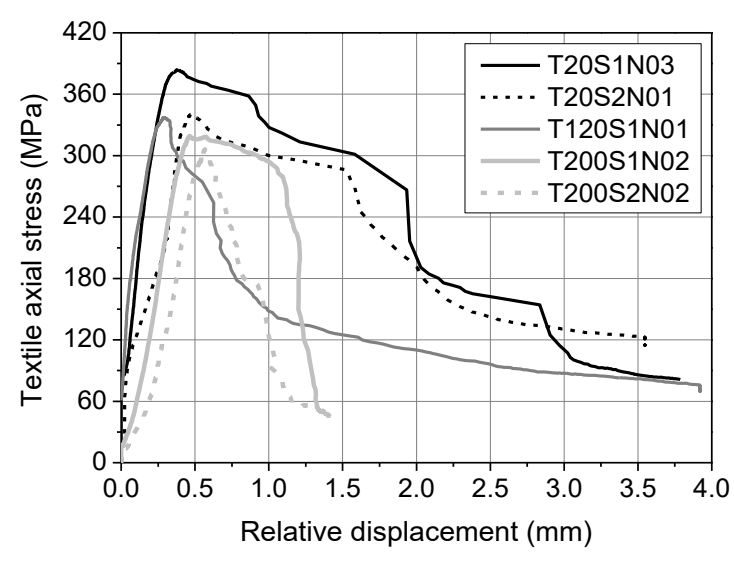

(a)

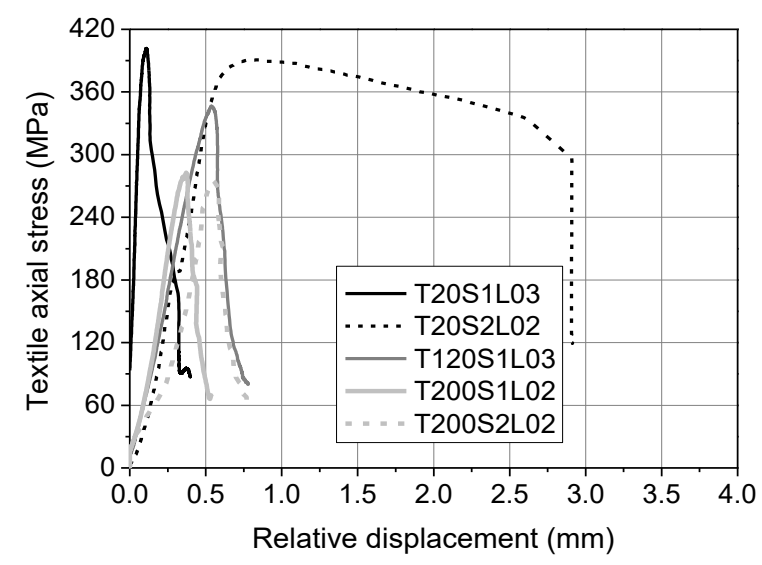

(b)

Figure 8. Response curves of representative specimens reinforced with: (a) TRNM and (b) TRLM overlays.

\section{Conclusions}

The main drive for use of lightweight matrices in TRMs is to provide heat shielding to the reinforcement (fibrous grid) since lightweight mortars are characterized by lower heat conductivity with respect to normal weight ones. Nevertheless, the design of lightweight aggregate (e.g., pumice) cement-based mortars suitable for TRMs (i.e., comparable to normal weight ones, in terms of-at least —strength) requires high strength pastes with low effective water-to-cementitious material ratios in order to compensate for the low crushing strength of the lightweight aggregates. The latter aggregates, which are often used in a fully saturated condition in the mixture, provide larger quantities of evaporable (and non-evaporable) moisture (in comparison to normal weight mortars) leading to: (i) early-age swelling (once wet curing is concluded), (ii) stress buildup during moisture evaporation by heating (dense paste causing high vapor pressure), and (iii) differential shrinkage cracking (along all TRM/masonry joints' interfaces). Hence, it is highlighted that a crucial parameter for the comparison of the post-heating residual shear bond response of different TRM systems on a reasonable basis is their moisture content. This must be kept at a constant (comparable) level, which is difficult to achieve and monitor. The main conclusions drawn from the experimental results presented in this work are summarized as follows. At control conditions (non-heated specimens) and after exposure at a nominal air temperature of $120^{\circ} \mathrm{C}$, both single-layer TRM systems (TRNM and TRLM) exhibit similar bond capacities. The same does not apply for the nominal exposure temperature of $200^{\circ} \mathrm{C}$ for which single-layer and double-layer TRNM overlays outperform the respective TRLM ones in terms of residual bond capacity. For TRLM overlays, the maximum textile axial stress decreases by $50 \%$ and $36 \%$ for specimens subjected to $200{ }^{\circ} \mathrm{C}$ with single-layer and double- layer overlays, respectively, in comparison to the maximum textile axial stress of the reference specimens. Increase of mortar thickness (to accommodate higher fiber volume fractions, i.e., more textile layers) seems to be beneficial in terms of post-heating residual bond capacity.

The relevant knowledge curve is at the beginning of its ascending branch. There are still many open questions to be answered (apart from the issue of moisture control). The object of the current study is a multi-parametric problem, which is hard to draw generalized conclusions from. There is a multitude of constituent material combinations comprising different TRM systems, which, in turn, can be combined with a vast array of different masonry substrates (all—adjacent materials—possessing different shrinkage strain potentials, porosity, and transport properties to mention a few). Per TRM/substrate combination, it would be interesting to assess the effects of hygro-thermal fatigue scenarios. 
Author Contributions: P.D.A. is the author of the draft manuscript. Additionally, she participated in the planning of the experimental program and was responsible for the construction/curing/handling of the specimens, the execution of the experimental program, the data treatment, and the derivation of preliminary conclusions. C.G.P. was in charge for the planning of the experimental program. She performed a critical evaluation of the experimental results and edited the manuscript. Lastly, M.I.K. was responsible for the mix design of the mortars. He also offered his help in the mechanical characterization of the materials used.

Funding: The research described in this paper has been co-financed by the European Union (European Social Fund-ESF) and Greek national funds through the Operational Program "Human resource development, education, and lifelong learning" of NSRF 2014-2020, Project "Supporting researchers with emphasis on young researchers-EDVM34".

Conflicts of Interest: The authors declare no conflict of interest.

\section{References}

1. Koutas, L.N.; Tetta, Z.; Bournas, D.A.; Triantafillou, T.C. Strengthening of Concrete Structures with Textile Reinforced Mortars: State-of-the-Art Review. J. Compos. Constr. 2019, 23, 03118001. [CrossRef]

2. Kouris, L.A.S.; Triantafillou, T.C. State-of-the-art on strengthening of masonry structures with textile reinforced mortar (TRM). Constr. Build. Mater. 2018, 188, 1221-1233. [CrossRef]

3. D' Antino, T.; Sneed, L.H.; Carloni, C.; Pellegrino, C. Influence of the substrate characteristics on the bond behavior of PBO FRCM-concrete joints. Constr. Build. Mater. 2015, 101, 838-850. [CrossRef]

4. Raoof, S.M.; Koutas, L.N.; Bournas, D.A. Bond between textile-reinforced mortar (TRM) and concrete substrates: Experimental investigation. Compos. B Eng. 2016, 98, 350-361. [CrossRef]

5. Askouni, P.D.; Papanicolaou, C.G. Experimental investigation of bond between glass textile reinforced mortar overlays and masonry: The effect of bond length. Mater. Struct. 2017, 50, 164. [CrossRef]

6. Askouni, P.D.; Papanicolaou, C.G. Textile Reinforced Mortar-to-masonry bond: Experimental investigation of bond-critical parameters. Constr. Build. Mater. 2019, 207, 535-547. [CrossRef]

7. Maroudas, S.R.; Papanicolaou, C.G. Effect of High Temperatures on the TRM-to-Masonry Bond. Key Eng. Mater. 2017, 747, 533-541. [CrossRef]

8. Ombres, L.; Iorfida, A.; Mazzuca, S.; Verre, S. Bond analysis of the thermally conditioned FRCM-masonry joints. Measurements 2018, 125, 509-515. [CrossRef]

9. Donnini, J.; De Caso y Basalo, F.; Corinaldesi, V.; Lancioni, G.; Nanni, A. Fabric-reinforced cementitious matrix behavior at high-temperature: Experimental and numerical results. Compos. B Eng. 2017, 108, $108-121$. [CrossRef]

10. Ombres, L. Analysis of the bond between Fabric Reinforced Cementitious Mortar (FRCM) strengthening systems and concrete. Compos. B Eng. 2015, 69, 418-426. [CrossRef]

11. Raoof, S.M.; Bournas, D.A. Bond between TRM versus FRP composites and concrete at high temperatures. Compos. B Eng. 2017, 127, 150-165. [CrossRef]

12. Pancar, E.B.; Akpinar, M.V. Temperature Reduction of Concrete Pavement Using Glass Bead Materials. Int. J. Concr. Struct. Mater. 2016, 10, 39. [CrossRef]

13. Oxfall, M. Climatic Conditions Inside Nuclear Reactor Containments: Evaluation of Moisture Condition in the Concrete within Reactor Containments and Interaction with the Ambient Compartments. Ph.D. Thesis, Lund University, Lund, Sweden, 2016.

14. CEN. EN 1996-1-1 Eurocode 6-Design of Masonry Structures-Part 1-1: General Rules for Reinforced and Unreinforced Masonry Structures; European Committee for Standarization: Brussels, Belgium, 2005.

15. RILEM TC 76: Technical Recommendations for Testing and Use of Constructions Materials: LUMB1-Compressive Strength of Small Walls and Prisms; Chapman \& Hall: London, UK, 1991.

16. CEN. EN ISO 13934-1: Textiles-Tensile Properties of Fabrics-Part 1: Determination of Maximum Force and Elongation at Maximum Force Using the Strip Method; British Standard: Brussels, Belgium, 1999.

17. CEN. EN 1015-11: Methods of Test for Mortar for Masonry-Part 11: Determination of Flexural and Compressive Strength of Hardened Mortar; European Committee for Standardization: Brussels, Belgium, 1993.

18. AC434 ICC-ES: Masonry and Concrete Strengthening Using Fiber-Reinforced Cementitious Matrix (FRCM) Composite Systems; ICC-Evaluation Service: Whittier, CA, USA, 2013. 
19. De Felice, G.; Aiello, M.A.; Caggegi, C.; Ceroni, F.; De Santis, S.; Garbin, E.; Gattesco, N.; Hojdys, Ł.; Krajewski, P.; Kwiecień, A.; et al. Recommendation of RILEM Technical Committee 250-CSM: Test method for Textile Reinforced Mortar to substrate bond characterization. Mater. Struct. 2018, 51, 95. [CrossRef]

20. Chandra, S.; Berntsson, L. Lightweight Aggregate Concrete, 1st ed.; William Andrew Publishing: William, CA, USA, 2003; pp. 291-319.

(c)

(C) 2019 by the authors. Licensee MDPI, Basel, Switzerland. This article is an open access article distributed under the terms and conditions of the Creative Commons Attribution (CC BY) license (http://creativecommons.org/licenses/by/4.0/). 